\title{
Colorado Asthma Toolkit Implementation Improves Some Process Measures of Asthma Care
}

\author{
Kathryn L. Colborn, PhD, MSPH, Laura Helmkamp, MS, Bruce G. Bender, PhD, \\ Bethany M. Kwan, PhD, MSPH, Lisa M. Schilling, MD, MSPH, \\ and Marion R. Sills, $M D, M P H$
}

Background: The Colorado Asthma Toolkit Program (CATP) has been shown to improve processes of care with less evidence demonstrating improved outcomes.

Objective: To model the association between pre-and-post-CATP status and asthma-related process and outcome measures among patients ages 5 to 64 years receiving care in safety-net primary care practices.

Methods: This is an implementation study involving secondary prepost analysis of existing structured clinical, administrative, and claims data. Nine primary care practices in a federally qualified health center network implemented the CATP. Processes of care and health and utilization outcomes were evaluated prepost implementation in a cohort of patients with asthma using generalized linear mixed models.

Results: The study cohort included 2678 patients age 5 to 64 years with at least one visit to one of the 9 participating practices during the study period (March 12, 2010 to December 1, 2012). A comparison of 12 months pre- and post-CATP implementation showed improvement in some process measures of asthma care associated with the intervention, including the rate of asthma-severity measurement, although no change in 2 Health care Effectiveness Data and Information Set measures: asthma medication ratio and medication management for people with asthma. We also found no change in asthma outcomes measured across multiple domains: exacerbations, utilization, symptom scores, and pulmonary physiology measures.

Conclusions: Implementation of the CATP in a primary care setting led to some improved processes of asthma care, but no changes in measured outcomes. Recommendations for future work include supplemental follow-up training including case review. (J Am Board Fam Med 2019;32:37-49.)

Keywords: Asthma, Colorado, Outcomes Assessment, Primary Health Care

Asthma is one of the most common chronic illnesses in the United States. In 2015, the overall prevalence of active asthma was $8.4 \%$ among children $(6.2 \text { million })^{1}$ and $7.6 \%$ among adults (18.4 million), ${ }^{2}$ and asthma is the lead diagnosis for 2.0

This article was externally peer reviewed.

Submitted 24 May 2018; revised 30 September 2018; accepted 2 October 2018.

From the Department of Biostatistics and Informatics, Colorado School of Public Health, University of Colorado Denver, Aurora, Colorado (KLC); Adult \& Child Consortium for Health Outcomes Research \& Delivery Science, Aurora, CO (LH); Department of Pediatrics, National Jewish Health, Denver (BGB); Department of Medicine, University of Colorado School of Medicine, Aurora (BMK, LMS); Pediatrics, University of Colorado School of Medicine, Aurora (MRS).

Funding: The work described in the article and the writing of the article were funded by grant 5R21HL123589-02 from the National Heart, Lung, and Blood Institute. million Emergency Department (ED) visits ${ }^{3}$ and 340,000 hospitalizations ${ }^{3}$ annually. When managed appropriately in primary care settings, asthma is a controllable disease, ${ }^{4}$ such that most asthma exacerbations-episodes of increased airway obstruction-are preventable. ${ }^{5}$ As asthma exacerbations are the reason for asthma-related ED visits, hospitalizations, missed school/work days, and deaths, evidence on effective disease management strategies is a priority for policy makers, ${ }^{6,7}$ payers, ${ }^{8}$ and researchers, ${ }^{9,10}$ with most interventions targeting the primary care setting. ${ }^{4,11}$

Conflict of interest: none declared.

Corresponding author: Kathryn L. Colborn, PhD, 13001 E. 17th Place, Room C3011, Aurora, CO 80045 (E-mail: Kathryn.colborn@ucdenver.edu). 
National asthma guidelines ${ }^{12}$ and subsequent reviews ${ }^{13-15}$ provide consistent guidance on what constitutes high-quality asthma care; nevertheless, clinicians' guideline concordance is inconsistent in primary-care settings. ${ }^{16-18}$ The need for guidelines-focused training in primary care is well established, ${ }^{19-21}$ but training programs have met with mixed success. Interventions designed to enhance diagnosis and management of respiratory diseases in primary-care settings have had variable success and have not been implemented broadly. ${ }^{22,23}$ The Colorado Asthma Toolkit Program (CATP) was introduced as a provider-level intervention to improve implementation of guidelines for high-quality asthma care through addressing known barriers and using known facilitators of implementation. ${ }^{24}$ Barriers to guideline implementation include lack of knowledge of guideline recommendations, doubt about the evidence base, and lack of time and resources. ${ }^{25,26}$ Facilitators of guideline implementation include improved teamwork, comprehensive training, and improvements in electronic record systems. $^{26-28}$

To improve guideline-concordance of asthma care in primary care, investigators from National Jewish Health (NJH) partnered with local stakeholders to develop both the content and implementation strategy for an intervention to address the known barriers to and facilitators of asthma treatment guideline concordance. The implementation strategy and content of the intervention - the CATP-was first developed in 2007 and addresses all 4 categories of provider-level asthma intervention. ${ }^{29}$ To date, 500 providers at 170 Colorado primary care practices serving safety-net patients have been trained using the CATP. ${ }^{30}$ As part of this program, NJH partnered with the Metro Community Provider Network $(\mathrm{MCPN})^{31}$ to implement the CATP in 9 practices in 2011. ${ }^{32} \mathrm{MCPN}$ is a network of health centers serving safety-net populations throughout metropolitan Denver. ${ }^{31}$ The MCPN CATP implementation was adapted from an earlier, stakeholder-designed version of the CATP that successfully changed practice behavior in 57 primary care offices in rural eastern Colorado. ${ }^{24}$ The CATP has been shown to improve guideline concordance of care processes related to spirometry, asthma action plans and inhaled corticosteroids; the 2 prior studies of the CATP did not assess patient oriented outcomes. ${ }^{24,32}$
Assessment of the impact of the CATP on processes and outcomes has been limited by the minimal resources typically present in safety-net practices for tracking asthma outcomes longitudinally. ${ }^{32,34}$ However, MCPN participates in the Scalable Architecture for Federated Translational Inquiries Network (SAFTINet), ${ }^{34,35}$ an Agency for Health Care Quality and Research-funded practice-based distributed research network supported by a sophisticated technical infrastructure that standardizes clinical and claims data to a common data model and links electronic health record (EHR) and claims data at the patient level to facilitate patient -outcomes research. ${ }^{36,37}$ The SAFTINet partner databases include both the clinical EHR data and Medicaid claims data necessary for operationalizing standard asthma outcome measures. ${ }^{38}$ The objective was to perform secondary data analysis of asthma process and outcome measures associated with implementation of the CATP at MCPN practices, using existing data from SAFTINet. We performed a prepost single-group study of the CATP implementation, using generalized linear mixed models (GLMMs) to evaluate prepost changes in processes and outcomes of care at the patient level (Figure 1). Specifically, these measures include use of spirometry, asthma severity assessment, and asthma action plan use among all asthmatics, and controller medication use, and medication ratios among persistent asthmatics. ${ }^{39}$ We hypothesized that patients in participating practices would have improved asthma control and fewer exacerbations after CATP implementation compared with preimplementation.

\section{Methods}

\section{Study Design and Setting}

We performed an implementation study involving secondary prepost analysis of existing structured clinical, administrative, and claims data. The data network from which study data were obtained is SAFTINet, a clinical and claims distritubed data network designed to securely share electronic health data to support quality improvement and research. The SAFTINet databases include existing administrative, clinical, Medicaid claims, patient-reported outcome data including the Asthma Control Test $(\mathrm{ACT}),{ }^{40}$ and enrollment data collected during routine clinical care. Data are standardized to the Observational Medical Outcomes Partnership common data model (Version 4; Observational Health Data Sciences and Informatics). ${ }^{41}$ The data 
Figure 1. Colorado Asthma Toolkit Program (CATP) Conceptual Model. Key content areas were introduced in 3 education and feedback/audit sessions, which were then reinforced via 3 other approaches: 1) organizational change to optimize efficieny integrating CATP processes into practice workflow; 2) decision support tools for asthma management; and 3) online resources to help reinforce and sustain practice changes.

\begin{tabular}{|l|l|l|}
\hline $\begin{array}{l}\text { Key components of care } \\
\text { (NIH guidelines) }\end{array}$ & $\begin{array}{l}\text { Key content areas of the CATP } \\
\text { implementation }\end{array}$ \\
\hline $\begin{array}{l}\text { Assessment and } \\
\text { monitoring }\end{array}$ & $\begin{array}{l}\text { Assessment and monitoring, } \\
\text { including use of the ACT } \\
\text { education }\end{array}$ \\
\hline $\begin{array}{l}\text { Asthma care } \\
\text { environmental } \\
\text { factors and } \\
\text { comorbid conditions }\end{array}$ & $\begin{array}{l}\text { Spirometry administration } \\
\text { and interpretation }\end{array}$ \\
\hline $\begin{array}{l}\text { Pharmacologic } \\
\text { therapy }\end{array}$ & $\begin{array}{l}\text { Adherence and patient } \\
\text { education }\end{array}$ \\
\hline
\end{tabular}

are limited data sets as defined by the Health Insurance Portability and Accountability act, deidentified with the exception of service dates, birth dates for those $<90$ years old, and zip codes.

We requested data from the MCPN SAFTINet database for patients who had experienced at least 1 encounter during the study period at least one of the 9 participating practices. Electronic health data from the SAFTINet databases was used to select patients for inclusion in the cohorts, to operationalize patient-level outcomes and covariates, and to associate patients with practices.

\section{Cobort Selection}

Inclusion criteria included age between 5 and 64 years by the start of the study period (March 12, 2010 to December 1, 2012); at least one visit to an MCPN practice during the study period; at least 1 month of Medicaid eligibility during the study period; and either an asthma diagnosis or an asthmaspecific medication. As our primary outcome measure and other measures included criteria available only in claims (Colorado Medicaid) data, we excluded patients who had no months of Medicaid coverage during the study period. Given the chronic nature of asthma, for asthma diagnosis events, we included any asthma diagnostic code or string assigned for the patient during the study period or 5 years before study inception. As asthma-specific medications, we included any prescription or fulfillment of at least 1 medication from the Health care Effectiveness Data and Information Set (HEDIS) list, "Asthma Controller and Reliever Medications," that occurred during the study period. ${ }^{42} \mathrm{We}$ in- cluded the same cohort in both the pre- and postintervention study periods. For more details on the definitions used for asthma diagnosis events and asthma-specific medications, please see the Technical Appendix.

\section{Intervention}

Four provider-level asthma intervention categories $^{29}$ - decision support, organizational change, audit and feedback, and education-have been shown to be effective in improving the quality of primary asthma care processes. ${ }^{5,43}$ These were all incorporated into the CATP implementation as follows.

1) Education and feedback/audit: All clinical care team members were invited to 3 training sessions led by a nurse practice coach. A practicecoaching strategy was used to emphasize teamwork and to develop a practice-specific asthma protocol. Session 1 was 7 hours, with content in 6 modules: 1) assessment and monitoring, including use of the ACT, 2) spirometry administration and interpretation, 3) asthma tools and techniques, 4) adherence and patient education, 5) nonpharmacologic management, and 6) case studies. Sessions 2 and 3 were 3 hours long and reviewed module content, spirometry technique, collaborative self-management, and specific cases. For the ACT, clinical care teams administered the childhood version for children age 5 to 11 years (asking the parent to complete it on behalf of the child) and the adult version for ages 12 to 64 years.

2) Organizational change: At each session, the practice coach used interactive discussion to de- 
velop a practice-specific asthma protocol aimed at optimizing efficiency in integrating CATP processes into practice roles and workflow. Practice members were also asked to identify an "asthma champion" to help lead implementation of the practice-specific asthma protocol.

3) Written and computerized clinical decision support: Each provider received a provider manual containing all content from the training, a spirometry guide, and copies of the ACT and an asthma action plan. The CATP EHR asthma template includes severity assessment tools and decision support guiding initial asthma management and recommended actions for ongoing management based on asthma control.

4) Online resources: Providers were given access to online support to help reinforce and sustain practice changes, including an Asthma Toolkit Web site and Facebook page. These were made accessible to trained and new MCPN providers. The Web site contains training module videos and provider training manuals. The Facebook page permits providers and the NJH CATP team to interact about the CATP.

\section{Study Periods}

The intervention period for the CATP was March 12, 2011 to December 1, 2011. We selected a 1 -year pre- and postintervention period (March 12, 2010 to March 11, 2011 and December 2, 2011 to December 1, 2012) for our analysis.

\section{Process Measures Related to Guideline Concordance of Asthma Care}

To evaluate the implementation, we selected and assessed several process measures directly related to the content in the CATP training program, as shown in the study's conceptual model (Figure 1). ${ }^{24}$ Each process measure was assessed at the patient level, resulting in separate, dichotomous variables indicating concordance (yes/no) for the pre- and post-CATP periods. The investigators selected process measures for inclusion based on their use in the initial evaluation of the MCPN CATP intervention, their consistency with the conceptual model (Figure 1), their relevance to the National Institutes of Health asthma guidelines, and their endorsement by the National Quality Forum (NQF).

The 2 NQF-endorsed HEDIS asthma-process measures were the Medication Management for
People with Asthma (the percentage of individuals 5 to 64 years of age who were identified as having persistent asthma and were dispensed appropriate asthma controller medications that they remained on for at least $75 \%$ of the period) and the Asthma Medication Ratio (the percentage of individuals 5 to 64 years of age who were identified as having persistent asthma and had a ratio of controller medications to total asthma medications of 0.50 or greater during the measurement year). ${ }^{39}$ The denominator for these 2 measures is "persistent asthma," defined via both HEDIS measure specifications as having at least 1 of the following during each of 2 successive years: an asthma-specific ED visit or inpatient visit, at least 4 outpatient asthma visits plus at least 2 asthma-specific medications, or at least 4 asthma-specific medications. We used only Medicaid claims data to calculate HEDIS measure values, as instructed in the HEDIS measure specifications ${ }^{39}$ (more details in Technical Appendix). We chose not to also include EHR data in calculating these measures to avoid including duplicate records of medications or visits from the 2 data sources (EHR and claims).

We included asthma control measurementsboth spirometry and ACT-as process measures (how many were assessed in each period) and as outcome measures based on the value of each measure. We assessed spirometry performance based on procedure codes.

\section{Outcome Measures}

To evaluate the effectiveness of the CATP, we evaluated a variety of health and utilization outcomes. The study used 4 categories of outcomes recommended for observational studies by the Asthma Outcomes Workshop convened by the $\mathrm{Na}$ tional Institute of Health and Agency for Health care Research and Quality. ${ }^{39}$ These include exacerbations ${ }^{44}$ (primary outcome), health care utilization, ${ }^{45}$ composite scores, ${ }^{50}$ and pulmonary physiology measures. ${ }^{47}$

We defined the primary outcome measure, asthma exacerbations, using the recommended observational study standards for exacerbation measurement from the Asthma Outcomes workshop. ${ }^{44}$ Specifically, we defined an exacerbation as at least 1 of the following qualifying events, with qualifying events occurring within 14 days of each other defining a single exacerbation. 
1) An emergency department or inpatient visit with a primary diagnostic code for asthma.

2) A cluster of 2 visits of at least one of the following 2 types within 1 and 14 days: a) an outpatient visit (primary care or subspecialty) with a primary diagnostic code for asthma, or b) an ED, inpatient (IP), or outpatient visit with any diagnostic code (not just primary) for asthma. We excluded visits on the same day to avoid double counting the same visit.

3) Any ED, IP, or outpatient visit with an ICD-9 code for asthma that has a fifth digit, or a diagnosis text string, indicative of an exacerbation.

4) Any prescription or fulfillment of a systemic corticosteroid medication from 0 to 3 days after the date of any type of visit where the visit includes a diagnostic code for asthma. Medication codes for systemic steroids were identified using Generic Product Identifier (GPI) codes. As prescription duration data showed high rates of missing data, we did not include steroid prescription duration in this definition.

For exacerbation criteria events, and 2 events within a 14-day span were considered the same exacerbation; thus, 3 or more events could create an exacerbation with a duration of more than 14 days. This is based on evidence showing a median 10-to14-day duration of typical asthma exacerbations. ${ }^{48}$ For further details of the exacerbation definition, please see the Technical Appendix.

In accordance with the Asthma Outcomes Workshop recommendations, we also provide descriptive statistics on the specific components of the exacerbation definition: asthma-specific ED, IP, and outpatient $(\mathrm{OP})$ visits, and steroid prescriptions. We also provide summary statistics for the other categories of asthma medications prescribed in each period.

The second category of outcome measures is health care utilization events. Here we report each of the 3 visit type categories-IP, ED, and $\mathrm{OP}$ - as well as asthma-specific medication use (reliever or controller medications). Due to duplicate medications occurring within both the clinical and claims data, we deduplicated medication records by person, start date, and by GPI code to avoid double counting the same prescription.

The third category of outcome measures is composite symptom scores-namely, the ACT values. The range for the ACT is 5 to 25 and the Childhood ACT range is 0 to 27 . For both versions, a score less than 19 is considered poor control and thus ACT results were dichotomized at 19.

The fourth category of outcome measures is physiologic measures, including the results of spirometry (FEV1/FVC ratio percent predicted values $^{49,50}$ ) and of peak expiratory flow monitoring. For descriptive statistics, the median was reported for patients with $>1$ observation recorded. For analyses, we dichotomized forced expiration at $80 \%$ of the FEV1 predicted value.

\section{Covariates}

We adjusted for those variables available in the dataset that were potential confounders of the association between the CATP and asthma control. These include patient demographics (age, sex, race/ethnicity), health care insurance coverage and chronic medical complexity. We categorized age using the categories defined in the age-specific guideline recommendations in the National Asthma Education and Prevention Program guideline on asthma management. ${ }^{5}$ We categorized race and ethnicity using the categories present in MCPN's EHR. Race and ethnicity are documented through each clinic's patient registration process at the time of initial registration in the MCPN system.

We defined health care insurance coverage as the number of months of Medicaid eligibility for each patient during the study period. Because we limited the cohort to patients with at least 1 month of Medicaid eligibility, our sample included no patients with zero months of eligibility.

To measure medical complexity of each patient in the cohort, we used the Health care Cost and Utilization Project's Chronic Condition Indicator (CCI) tool's 17 body system categories. For each patient, we counted the number of body systems affected by CCIs, excluding the category for diseases of the respiratory system, as every cohort member had a condition in this category (asthma). ${ }^{51}$

\section{Statistical Methods}

GLMMs were used to evaluate prepost changes in process, health, and utilization outcomes withinpatient. A random effect was included to account for correlation among observations from the same clinic. Models where comparisons were made between preintervention and postintervention on paired data from individuals also included a random effect for individual-level correlation. Count vari- 
Figure 2. The study cohort flow diagram.

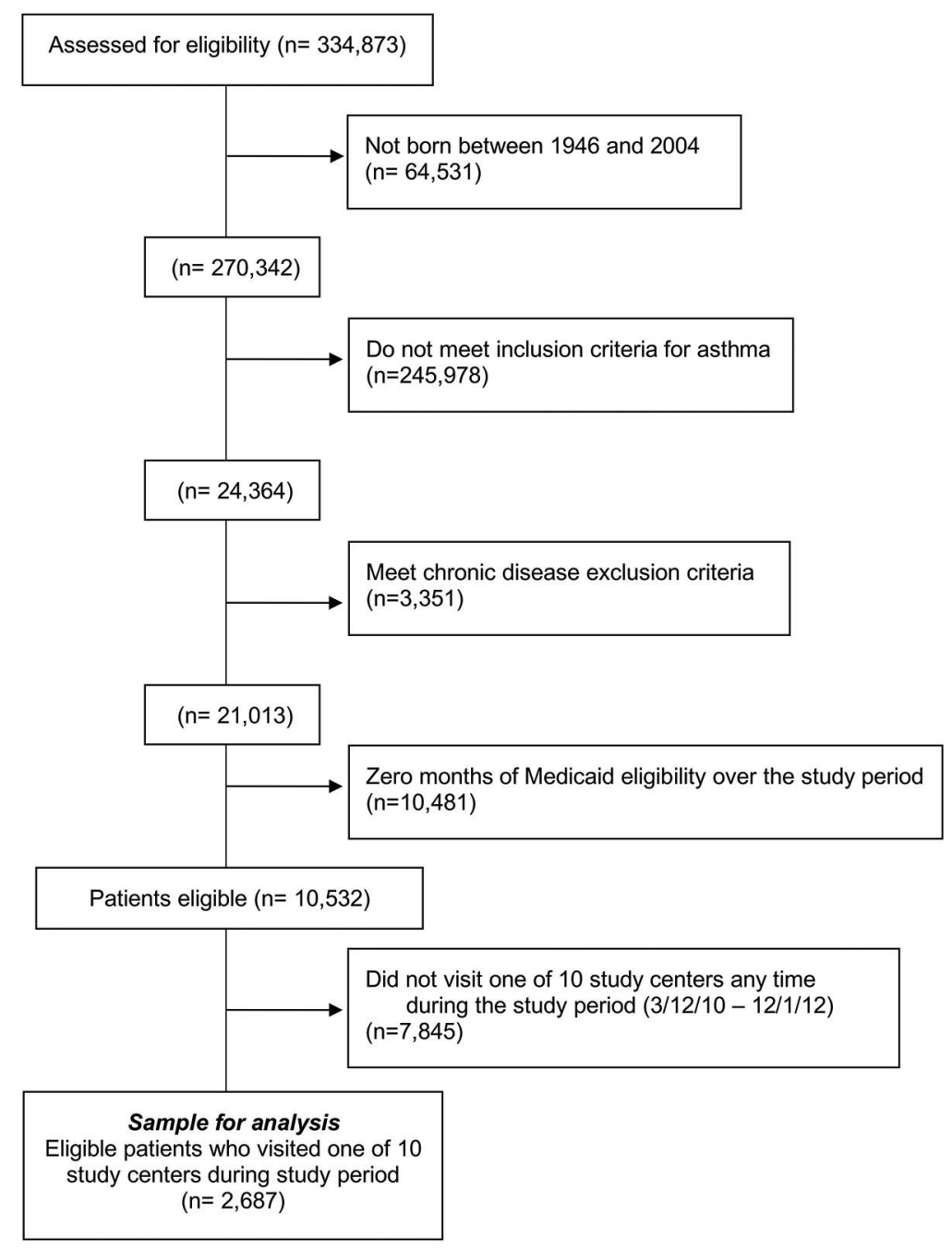

ables were assumed to follow Poisson distributions when the means were approximately equal to the variances. For all binary outcomes, binomial GLMMs were fit with logit link functions. Data cleaning was performed in $\mathrm{R}$ ( $\mathrm{R}$ Project for Statistical Computing, Vienna, Austria, Version 3.3.3) and SAS (Version 9.4m4, Cary, NC) and all models were fit in SAS using the PROC GLIMMIX procedure.

\section{Results}

\section{Sample Characteristics}

After applying inclusion and exclusion criteria, the resulting asthma study cohort included 2687 patients (Figure 2). The median age was 23 years, with $58.3 \%$ of patients in the adult age range (18 to 64 years), and $66.5 \%$ were female (Table 1 ). More than half $(51.8 \%)$ had unknown race, with $32.5 \%$ reported as white race and $10.9 \%$ as black race. By ethnicity, 31.8\% were Hispanic/Latino, 46.7\% were not Hispanic/Latino and $21.6 \%$ had unknown ethnicity. The count of comorbidity categories were as follows: $12.6 \%$ had none and $52.1 \%$ had more than 2. The median duration of Medicaid eligibility was the full study period duration-33 months-with $89.5 \%$ having at least 20 months of eligibility.

\section{Process Outcomes}

For process measures, rates pre- and postintervention were mixed (See Table 2. Both types of asthma severity assessment-spirometry and ACT performance-increased significantly from pre- to postintervention; Table 2) The 2 NQF-endorsed HEDIS process measures-asthma medication ratio and medication management for people with 
Table 1. Asthma Cohort Demographics

\begin{tabular}{|c|c|}
\hline Variable & $\begin{array}{c}\text { Asthma } \\
\text { Cohort } \\
(\mathrm{n}=2678)\end{array}$ \\
\hline \multicolumn{2}{|l|}{ Age group, n (\%) } \\
\hline 5 to 11 years & $747(27.8)$ \\
\hline 12 to 17 years & $374(13.9)$ \\
\hline 18 to 64 years & $1566(58.3)$ \\
\hline \multicolumn{2}{|l|}{ Sex } \\
\hline Male & $899(33.5)$ \\
\hline Female & $1788(66.5)$ \\
\hline \multicolumn{2}{|l|}{ Race, n (\%) } \\
\hline White & $874(32.5)$ \\
\hline Black/African American & $294(10.9)$ \\
\hline Other & $128(4.8)$ \\
\hline Unknown & $1391(51.8)$ \\
\hline \multicolumn{2}{|l|}{ Ethnicity } \\
\hline Hispanic/Latino & $854(31.8)$ \\
\hline Not Hispanic/Latino & $1254(46.7)$ \\
\hline Unknown & $579(21.6)$ \\
\hline \multicolumn{2}{|l|}{ Comorbidity count, $\mathrm{n}(\%)^{*}$} \\
\hline 0 & $340(12.7)$ \\
\hline 1 & $522(19.4)$ \\
\hline 2 & $425(15.8)$ \\
\hline$>2$ & $1400(52.1)$ \\
\hline $\begin{array}{l}\text { Medicaid eligibility [months of } 33 \text { study } \\
\text { months], (median, IQR) }\end{array}$ & $33(31$ to 33$)$ \\
\hline
\end{tabular}

*Number of Healthcare Cost and Utilization Project (HCUP) Chronic Condition Indicator (CCI) "body systems" wherein the patient has one or more comorbidities, excluding respiratory. IQR, interquartile range.

asthma-did not change significantly from pre-to postintervention, although the percentage of patients meeting the HEDIS definition criteria for "persistent asthma" (the measure denominator for both measures) did increase significantly from $4.8 \%$ to $8.5 \%$ of the cohort, largely driven by more patients meeting medication-dispensing criteria for asthma in the postintervention period.

\section{Health Outcomes}

Exacerbations

As shown in Table 3, during the study period, 581 (21.6\%) patients experienced at least 1 asthma exacerbation, with a total of 1063 exacerbations; 356 experienced 1 exacerbation, 119 experienced 2, 52 experienced 3 , and the remaining 54 experienced 4 or more exacerbations. The rate of exacerbations did not change between pre- and postintervention, nor did the proportion with each of the 4 exacer- bation qualifying events in our study definition of exacerbation.

Of the 4 qualifying events in the study definition of an exacerbation, the most common was a type 4 event (systemic corticosteroid medication, 728 events), although we found that many exacerbations were characterized by more than 1 event type (Figure 3). For example, of the 728 exacerbations that included a type 4 event, 433 included at least 1 other qualifying event type. None of the event types changed in frequency between the pre- and postintervention periods (Table 3 ).

\section{Utilization Outcomes}

As shown in Table 3, for the utilization outcomes, the number of $\mathrm{ED}$, IP, and $\mathrm{OP}$ visits for asthma were similar pre- and postintervention. The number of asthma-specific medication events (prescriptions, dispensing events) rose by $36.3 \%$ from 5221 to 7116 . This increase occurred for both controller medications (34.3\% rise) and relievers ( $37.7 \%$ rise).

We could not analyze composite asthma score values as an outcome as there were no ACTs measured in the preintervention period. This was expected, as the ACT was part of the intervention. For our pulmonary physiology outcome, we found

Figure 3. Distribution of exacerbations by qualifying event. Type 1: single Emergency Department (ED) or inpatient (IP) visit with primary diagnosis of asthma. Type 2: cluster of 2 visits with asthma diagnosis $<14$ days apart. Type 3: ICD code or string indicating exacerbation. Type 4: systemic corticosteroid within 0 to 3 days after any type of asthma visit. Note: exacerbations occurring within 14 days of each other were grouped into a single exacerbation.

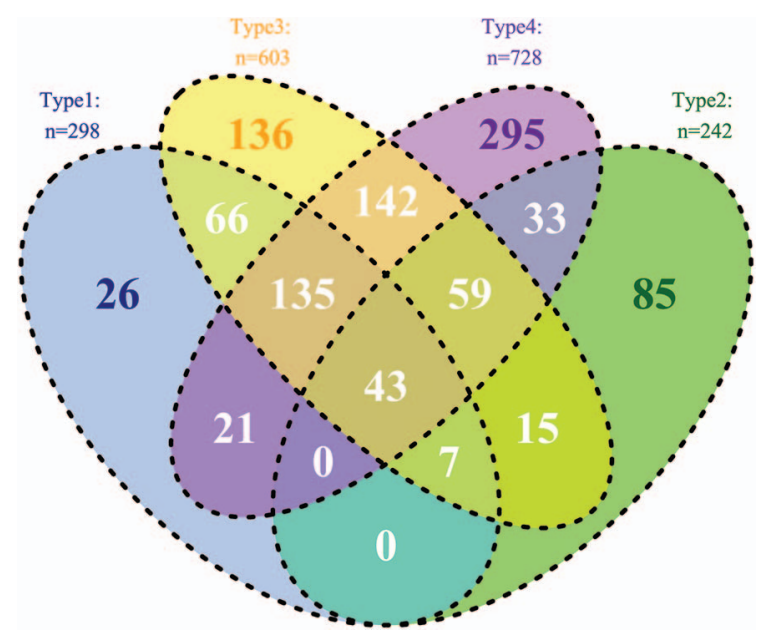




\begin{tabular}{|c|c|c|c|}
\hline & Pre-Intervention & Post-Intervention & $P$ Value \\
\hline \multicolumn{4}{|l|}{ Asthma severity assessed } \\
\hline Spirometry performed, N, (\% of patients) & $32(1.2 \%)$ & $272(10.1 \%)$ & $.003^{1,2}$ \\
\hline ACT assessed, $\mathrm{N}$, (\% of patients) & $0(0.0 \%)$ & $310(11.5 \%)$ & N/A \\
\hline \multicolumn{4}{|l|}{ HEDIS measures } \\
\hline $\begin{array}{l}\text { Patients meeting inclusion criteria for HEDIS definition of } \\
\text { persistent asthma (\% of study sample) }\end{array}$ & $129(4.8 \%)$ & $228(8.5 \%)$ & $<.0001^{1}$ \\
\hline $\begin{array}{l}\text { Asthma medication ratio: percentage identified as having persistent } \\
\text { asthma who had a ratio of controller medications to total } \\
\text { asthma medications of } 0.50 \text { or greater }\end{array}$ & $52.3 \%$ & $58.5 \%$ & .3 \\
\hline \multicolumn{4}{|l|}{$\begin{array}{l}\text { Medication management for people with asthma: percentage } \\
\text { identified as having persistent asthma who were dispensed an } \\
\text { asthma controller medication that they remained on for at } \\
\text { least: }\end{array}$} \\
\hline $75 \%$ of their treatment period & $27.6 \%$ & $34.2 \%$ & .2 \\
\hline $50 \%$ of their treatment period & $56.9 \%$ & $63.2 \%$ & .3 \\
\hline
\end{tabular}

All $P$ values in this table obtained using generalized linear mixed models with random effects to control for variability between clinics. Random effects for subject were included when 1) applicable, and 2) random treatment effects by clinic were included when significant.

ACT, Asthma Control Test; HEDIS, Health care Effectiveness Data and Information Set.

no change in the FEV1/FVC percent predicted values pre- to postintervention.

\section{Discussion}

In this prepost analysis of the CATP in one network of federally qualified health centers, we found improvement in some process measures of asthma care associated with the intervention: increased use of spirometry and administration of the ACT measure. At the same time, no change occurred in the 2 HEDIS asthma process measures: asthma-medication ratio and medication management for people with asthma. We also found no change in asthma outcomes measured across multiple domains: exacerbations, utilization, symptom scores, and pulmonary physiology measures.

These findings are similar to those of prior studies of asthma care processes associated with CATP implementation. One prior study of the CATP found that practices reported they increased their use of inhaled corticosteroids, increased their use of asthma action plans, and initiated or increased their use of spirometry. ${ }^{24}$ An analysis of the MCPN CATP intervention using only EHR data found increased use of spirometry, severity assessments, asthma action plans, and prescription of inhaled corticosteroids. ${ }^{32}$ Although we could not measure asthma action plan use in our current study, we confirmed using SAFTINet data that both spirometry and ACT measurement improved. Unlike these 2 prior CATP studies, the current study also assessed asthma outcomes but found no change.

A plethora of evidence using the Reach-Effectiveness-Adoption-Implementation-Maintenance (RE-AIM) Framework has shown that consistent implementation of an intervention (eg, CATP process of care) is prerequisite for realizing effectiveness in real-world care settings. ${ }^{52,53}$ The lack of effects on outcomes in this study may be attributable to the limited changes in guideline-adherent process of care. While spirometry and ACT use increased, simply measuring asthma control was not enough to change either medication management (reflected in the 2 HEDIS measures) or patient outcomes (Figure 1). Further attention to taking action on observing poor control is needed. The finding that measuring asthma control is not sufficient to make an impact reflects findings from other domains of primary care-for instance, implementation of the PHQ-9, a recommended tool for measuring symptoms of depression, does not in and of itself improve depression outcomes. ${ }^{54}$

Among our secondary outcomes, the only change was a rise in the number of asthma controller and reliever medications prescribed or fulfilled. This increase also explained the rise in the number of patients meeting HEDIS measure denominator criteria (persistent asthma). This is consistent with the rise in controller medication administration reported in the 2 prior CATP studies. ${ }^{24,32}$ 
Table 3. Outcome Measures

\begin{tabular}{|c|c|c|c|}
\hline Exacerbation Events & Pre-Intervention Period & Post-Intervention Period & $P$ Value \\
\hline Total exacerbations & 386 & 414 & \\
\hline Patients with no exacerbations, N (\%) & $2410(89.7)$ & $2389(88.9)$ & $.3^{\ddagger}$ \\
\hline $\begin{array}{l}\text { Exacerbations per person among those with } 1 \\
\text { or more exacerbations, Median (IQR) (min, } \\
\text { max) }\end{array}$ & $1(1-1)(1,9)$ & $1(1-1)(1,8)$ & $1.0^{\ddagger}$ \\
\hline \multicolumn{4}{|l|}{$\begin{array}{l}\text { Percent of exacerbations with a qualifying event } \\
\text { of type:* }\end{array}$} \\
\hline $\begin{array}{l}\text { Type 1: single ED or IP visit with primary } \\
\text { diagnosis of asthma }\end{array}$ & $112 / 386(29.0)$ & $109 / 414(26.3)$ & $.3^{\ddagger}$ \\
\hline $\begin{array}{l}\text { Type 2: cluster of } 2 \text { visits with } 1 \text { to } 14 \text { days } \\
\text { between, both with an asthma diagnosis }\end{array}$ & $85 / 386(22.0)$ & $89 / 414(21.5)$ & $.5^{\ddagger}$ \\
\hline $\begin{array}{l}\text { Type 3: ICD code (5th digit) or string } \\
\text { indicating exacerbation }\end{array}$ & $220 / 386(57.0)$ & $245 / 414(59.2)$ & $.3^{\ddagger}$ \\
\hline $\begin{array}{c}\text { Type 4: systemic corticosteroid within } 0 \text { to } 3 \\
\text { days after any type of visits for asthma }\end{array}$ & $265 / 386(68.7)$ & $275 / 414(66.4)$ & $.4^{\ddagger}$ \\
\hline \multicolumn{4}{|l|}{ Healthcare utilization } \\
\hline $\begin{array}{l}\text { 1. IP visits with primary asthma diagnosis } \\
\text { (number of visits) }\end{array}$ & 5 & 1 & - \\
\hline $\begin{array}{l}\text { 2. ED visits with primary asthma diagnosis } \\
\text { (number of visits) }\end{array}$ & 131 & 121 & - \\
\hline $\begin{array}{l}\text { 3. Outpatient visits with an asthma diagnosis } \\
\text { (number of visits) }\end{array}$ & 1888 & 1910 & - \\
\hline $\begin{array}{l}\text { 4. Asthma-specific medication use ( } \mathrm{n} \\
\text { prescriptions) }^{\dagger}\end{array}$ & 5,221 & 7,116 & - \\
\hline 4a. Controller use & 2,224 & 2,987 & \\
\hline 4b. Reliever use & 2,997 & 4,129 & \\
\hline \multicolumn{4}{|l|}{$\begin{array}{l}\text { Healthcare utilization-number of patients with } \\
\text { at least } 1 \text { of the following: }\end{array}$} \\
\hline 1. IP visit with primary asthma diagnosis & $5 / 2687(0.2)$ & $1 / 2687(0.0)$ & .1 \\
\hline 2. ED visit with primary asthma diagnosis & $83 / 2687(3.1)$ & $92 / 2687(3.4)$ & .4 \\
\hline 3. Outpatient visits with an asthma diagnosis & 609/2687 (22.7) & 649/2687 (24.2) & .1 \\
\hline 4. Asthma-specific medication use ${ }^{\dagger}$ & $1094 / 2687(40.7)$ & $1334 / 2687(49.6)$ & $<.0001$ \\
\hline 4a. Controller use & $468 / 2687(17.4)$ & $585 / 2687(21.8)$ & $<.0001$ \\
\hline 4b. Reliever use & $1005 / 2687(37.4)$ & $1240 / 2687(46.2)$ & $<.0001$ \\
\hline \multicolumn{4}{|l|}{ Composite scores: ACT } \\
\hline Observations, $\mathrm{N}$ & 0 & 543 & - \\
\hline ACT score = "in control," $\mathrm{n}$ (\% of all ACTs $)$ & $\mathrm{n} / \mathrm{a}$ & $325(60.2)$ & - \\
\hline ACT score = "poorly controlled," n (\%) & $\mathrm{n} / \mathrm{a}$ & $132(24.4)$ & - \\
\hline ACT score = "very poorly controlled," n (\%) & $\mathrm{n} / \mathrm{a}$ & $83(15.4)$ & - \\
\hline \multicolumn{4}{|l|}{$\begin{array}{l}\text { Pulmonary physiology: FEV1/FVC percent } \\
\text { predicted }\end{array}$} \\
\hline Observations, $\mathrm{N}$ & 13 & 456 & - \\
\hline Mean value, \% predicted, (standard deviation) & $82.5(11.1)$ & $77.9(13.1)$ & $.1^{\ddagger}$ \\
\hline
\end{tabular}

ACT, asthma control test; ED, emergency department; IP, inpatient; OP, outpatient; IQR, interquartile range.

*Percentages add up to greater than $100 \%$ as an exacerbation may have more than one qualifying event.

${ }^{\dagger}$ This includes controllers and relievers but not steroids.

${ }^{\ddagger}$ Random effects for subject were included when applicable.

Targeting specific provider behaviors reflecting change in processes of care is important because practice change is an essential step toward changing outcomes. Nonetheless, as reflected in these findings, changing provider behaviors is no guarantee of change in outcomes, which are influenced by a host of variables including patient-level adherence to treatment ${ }^{55}$ and the unique characteristics of the patient population served by the practice and the characteristics and context of the practices themselves. ${ }^{56}$ Further improvements in provider behaviors may yield greater effectiveness at the patient 
level. A survey of 784 primary care providers concluded that continuing medical education programs addressing respiratory disease management had not adequately reached primary care practices, and that clinicians were less interested in attending distant sessions with opinion leaders, preferring live presentations, information they could access from their office, and content relevant to their daily practice. ${ }^{57}$ Tailored approaches that engage providers and include multiple opportunities for interaction and feedback are markedly more likely to change practice behavior. ${ }^{58}$ These training guidelines have been adopted in the CATP.

Still, additional research is needed to further improve CATP training and with it to improve patient outcomes. Results from this study of processes of change can help inform such refinements to the CATP, continuing to improve care delivery with the objective of decreasing asthma symptoms and health care utilization. Informal feedback from providers participating in CATP have indicated a desire for more follow-up training to include spirometry interpretation and decision support through case studies. Future directions include exploration of which elements of the provider-level CATP implementation are most effective in improving process measures, and in collecting process and outcome measures more specifically related to the components of the CATP intervention. For example, if future training involves more emphasis on ACT interpretation and decision support-shown to improve outcomes elsewhere-future process and outcome measures could quantify provider concordance with recommended responses to ACT values, and the associated asthma symptom burden or exacerbation in the weeks following each ACT measurement.

The current study also describes the distribution of asthma exacerbation events operationalized using hybrid (claims-and-EHR) data. Although prior studies have used the Asthma Outcomes standards for exacerbations, ${ }^{44,59}$ we found no prior studies detailing the distribution of exacerbations defined using observational data by type of qualifying event. The fact that 295 exacerbations were characterized by systemic corticosteroid prescribing or prescription-filling alone suggests that these may represent a different, milder form of exacerbation than those exacerbations also characterized by asthma-related ED and/or inpatient events.
Several types of bias are possible given the prepost, nonexperimental design, including selection bias and confounding. Selection bias (nonrandom selection into the study population) could be introduced by improved asthma detection-perhaps more so with milder asthma severity-following the intervention. As we included the same study population in both pre- and postintervention study populations, this bias is unlikely to impact our findings. Confounding may have been introduced by a secular trend-for example, if the pre- or postintervention periods differed in the severity of asthma triggers in the regional environment, such as seasonal allergens or circulating respiratory viruses. Given the lack of a control group, any number of other influences on asthma processes of care may have led to the effects observed in this study. Subsequent research should include pragmatic trial and quasi-experimental designs to test both the implementation and the effectiveness of CATP in diverse clinical settings. ${ }^{64}$

In conclusion, although we found improvement in some process measures of asthma care in this prepost analysis of the CATP in one network of practices, we found no change in asthma outcomes measured across multiple domains: exacerbations, utilization, symptom scores, and pulmonary physiology measures. Future directions may include a randomized trial of the toolkit in another setting, and subgroup analysis of findings based on exacerbation-qualifying events.

To see this article online, please go to: http://jabfm.org/content/ 32/1/37.full.

\section{References}

1. National Center for Health Statistics. Table C-1a. Age-adjusted percentages (with standard errors) of ever having asthma and still having asthma for children under age 18 years, by selected characteristics: United States, 2015. Centers for Disease Control and Prevention; 2015.

2. National Center for Health Statistics. Table A-2a. Age-adjusted percentages (with standard errors) of selected respiratory diseases among adults aged 18 and over, by selected characteristics: United States, 2015. Centers for Disease Control and Prevention; 2015.

3. HCUPnet, Healthcare Cost and Utilization Project. 2014. Available from: https://hcupnet.ahrq.gov/ \#setup. Accessed February 2, 2018.

4. Fuhrman C, Dubus JC, Marguet C, et al. Hospitalizations for asthma in children are linked to under- 
treatment and insufficient asthma education. J Asthma 2011;48:565-71.

5. National Asthma Education and Prevention Program. Expert panel report 3: Guidelines for the diagnosis and management of asthma. Bethesda, MD: National Heart, Lung, and Blood Institute; 2007, p. 53.

6. Office of Disease Prevention and Health Promotion. RD-2.2: Reduce hospitalizations for asthma among children and adults aged 5 to 64 years. Healthy People 2020 Objectives: Respiratory Diseases. 2016. Available from: http://www.healthypeople.gov/ 2020/topics-objectives/topic/respiratory-diseases/ objectives. Accessed January 28, 2016.

7. Agency for Healthcare Research and Quality. Pediatric quality indicators \#14 (PDI \#14) asthma admission rate. U.S. Department of Health and Human Services; 2015.

8. Pearson WS, Goates SA, Harrykissoon SD, Miller SA. State-based Medicaid costs for pediatric asthma emergency department visits. Prev Chronic Dis 2014;11:E108.

9. Kaur BP, Lahewala S, Arora S, et al. Asthma: Hospitalization trends and predictors of in-hospital mortality and hospitalization costs in the USA (20012010). Int Arch Allergy Immunol 2015;168:71-8.

10. Hasegawa K, Tsugawa Y, Brown DF, Camargo CA Jr. Childhood asthma hospitalizations in the United States, 2000-2009. J Pediatr 2013;163:1127-1133 e1123.

11. Szefler SJ. Advancing asthma care: The glass is only half full!. J Allergy Clin Immunol 2011;128: 485-94.

12. National Asthma Education and Prevention Program. Expert panel report 3 (EPR-3): Guidelines for the diagnosis and management of asthma-summary report 2007. J Allergy Clin Immunol 2007;120:S94S138.

13. Chauhan BF, Chartrand C, Ducharme FM. Intermittent versus daily inhaled corticosteroids for persistent asthma in children and adults. Cochrane Database Syst Rev 2013;2:CD009611.

14. Gibson PG, Powell H, Coughlan J, et al. Self-management education and regular practitioner review for adults with asthma. Cochrane Database Syst Rev 2003(1):CD001117.

15. Powell H, Gibson PG. Options for self-management education for adults with asthma. Cochrane Database Syst Rev 2003(1):CD004107.

16. Wisnivesky JP, Lorenzo J, Lyn-Cook R, et al. Barriers to adherence to asthma management guidelines among inner-city primary care providers. Ann Allergy Asthma Immunol 2008;101:264-70.

17. Diette GB, Wu AW, Skinner EA, et al. Treatment patterns among adult patients with asthma: Factors associated with overuse of inhaled beta-agonists and underuse of inhaled corticosteroids. Arch Intern Med 1999;159:2697-704.
18. Halterman JS, Aligne CA, Auinger P, McBride JT, Szilagyi PG. Inadequate therapy for asthma among children in the United States. Pediatrics 2000;105: 272-76.

19. Yawn BP, Rank MA, Cabana MD, Wollan PC, Juhn YJ. Adherence to asthma guidelines in children, tweens, and adults in primary care settings: A practice-based network assessment. Mayo Clin Proc 2016;91:411-21.

20. Gagne ME, Boulet LP. Implementation of asthma clinical practice guidelines in primary care: A crosssectional study based on the Knowledge-to-Action Cycle. J Asthma 2017;1-8.

21. Sokol KC, Sharma G, Lin YL, Goldblum RM. Choosing wisely: Adherence by physicians to recommended use of spirometry in the diagnosis and management of adult asthma. Am J Med 2015;128: 502-8.

22. Kaminsky DA, Marcy TW, Bachand M, Irvin CG. Knowledge and use of office spirometry for the detection of chronic obstructive pulmonary disease by primary care physicians. Respir Care 2005; 50:1639-48.

23. Lusuardi M, De Benedetto F, Paggiaro P, et al. A randomized controlled trial on office spirometry in asthma and COPD in standard general practice: Data from spirometry in Asthma and COPD: A comparative evaluation Italian study. Chest 2006; 129:844-52.

24. Bender BG, Dickinson P, Rankin A, Wamboldt F, Zittleman L, Westfall JM. The Colorado Asthma Toolkit Program: A practice coaching intervention from the High Plains Research Network. J Am Board Fam Med 2011;24:240-8.

25. Wiener-Ogilvie S, Pinnock H, Huby G, Sheikh A, Partridge MR, Gillies J. Do practices comply with key recommendations of the British Asthma Guideline? If not, why not? Prim Care Respir J 2007;16: 369-77.

26. Djandji F, Lamontagne AJ, Blais L, et al. Enablers and determinants of the provision of written action plans to patients with asthma: A stratified survey of Canadian physicians. NPJ Prim Care Respir Med 2017;27:21.

27. Morrow S, Daines L, Wiener-Ogilvie S, et al. Exploring the perspectives of clinical professionals and support staff on implementing supported self-management for asthma in UK general practice: An IMP2ART qualitative study. NPJ Prim Care Respir Med 2017;27:45.

28. Pinnock H, Epiphaniou E, Pearce G, et al. Implementing supported self-management for asthma: A systematic review and suggested hierarchy of evidence of implementation studies. BMC Med 2015; 13:127.

29. Okelo SO, Butz AM, Sharma R, et al. Interventions to modify health care provider adherence to asthma guidelines. Rockville, MD: Effective Health Care 
Program; May 2013. Comparative Effectiveness Review No. 95.

30. National Jewish Health. The Colorado Asthma Toolkit. Available from: http://coloradoasthmatoolkit. com. Accessed September 6, 2013.

31. The Metro Community Provider Network. Available from: http://www.mcpn.org/en/index.html. Accessed September 6, 2013.

32. Bender BG, Dingae MB, Fending D, Liu AH, Make B. Respiratory care training for safety-net primary care practices. Fam Med 2015;47:554-7.

33. Chang BL, Bakken S, Brown SS, et al. Bridging the digital divide: Reaching vulnerable populations. J Am Med Inform Assoc 2004;11:448-57.

34. The Scalable Architecture for Federated Translational Inquiries Network. Available from: http:// saftinet.net. Accessed September 6, 2013.

35. Kahn MG, Batson D, Schilling LM. Data model considerations for clinical effectiveness researchers. Med Care 2012;50:S60-S67.

36. Kahn MG, Schilling LM, Kwan BM, Bunting A, Uhrich C, Singleton C. Preparing electronic health records data for comparative effectiveness studies. Presented at the Healthcare Informatics, Imaging and Systems Biology (HISB), 2012 IEEE Second International Conference, San Diego, CA, September 27-28, 2012.

37. Schilling LM, Kwan BM, Drolshagen CT, et al. Scalable Architecture for Federated Translational Inquiries Network (SAFTINet) technology infrastructure for a distributed data network. Washington, DC: EGEMS; 2013;1:1027.

38. Busse WW, Morgan WJ, Taggart V, Togias A. Asthma outcomes workshop: Overview. J Allergy Clin Immunol 2012;129:S1-S8.

39. (NCQA.com. Medication Management for People with Asthma and Asthma Medication Ratio (MMA, AMR). Available from: http://www.ncqa.org/hedis/ measures/medication-management-for-people-withasthma-and-asthma-medication-ratio/. Accessed on 4/6/2018.

40. QualityMetric Incorporated. The Asthma Control Test. Available from: http://www.asthma.com/ resources/asthma-control-test.html.

41. Ong TC, Kahn MG, Kwan BM, et al. DynamicETL: A hybrid approach for health data extraction, transformation and loading. BMC Med Inform Decis Mak 2017;17:134.

42. Healthcare Effectiveness Data and Information Set NCQA.com. HEDIS 2016 Final NDC Lists. Table AMR-A: Asthma Controller and Reliever Medications. https://www.ncqa.org/hedis/measures/hedis2016-ndc-license/hedis-2016-final-ndc-lists/. Accessed on $4 / 6 / 2018$.

43. Global Initiative for Asthma, Pocket guide for asthma management and prevention. 2018. file:/// Users/katiecolborn/Downloads/wms-GINA-main- pocket-guide_2018-v1.0\%20(1).pdf. Accessed on 6/1/2018.

44. Fuhlbrigge A, Peden D, Apter AJ, et al. Asthma outcomes: Exacerbations. J Allergy Clin Immunol 2012;129:S34-S48.

45. Akinbami LJ, Sullivan SD, Campbell JD, et al. Asthma outcomes: Healthcare utilization and costs. J Allergy Clin Immunol 2012;129:S49-S64.

46. Cloutier MM, Schatz M, Castro M, et al. Asthma outcomes: Composite scores of asthma control. J Allergy Clin Immunol 2012;129:S24-S33.

47. Tepper RS, Wise RS, Covar R, et al. Asthma outcomes: Pulmonary physiology. J Allergy Clin Immunol 2012;129:S65-S87.

48. Benito-Fernández J. Short-term clinical outcomes of acute treatment of childhood asthma. Curr Opin Allergy Clin Immunol 2005;5:241-6.

49. Reddel HK, Taylor DR, Bateman ED, et al. An official American Thoracic Society/European Respiratory Society statement: Asthma control and exacerbations: Standardizing endpoints for clinical asthma trials and clinical practice. Am J Respir Crit Care Med 2009; 180:59-99.

50. Centers for Disease Control and Prevention. Spirometry Training Program: NHANES III Reference Values. 2010. Available from: http://www.cdc.gov/ niosh/topics/spirometry/nhanes.html. Accessed September 19, 2013.

51. Agency for Healthcare Research and Quality. Chronic Condition Indicator (CCI) for ICD-9-CM. Available from: https://www.hcup-us.ahrq.gov/tools software/chronic/chronic.jsp. Accessed February 6, 2017.

52. Glasgow RE, Klesges LM, Dzewaltowski DA, Estabrooks PA, Vogt TM. Evaluating the impact of health promotion programs: Using the RE-AIM framework to form summary measures for decision making involving complex issues. Health Educ Res 2006;21:688-94.

53. Gaglio B, Shoup JA, Glasgow RE. The RE-AIM framework: A systematic review of use over time. Am J Public Health 2013;103:e38-e46.

54. Kwan BM, Chadha S, Hamer MK, Spagnolo D, Kee S. Mixed methods evaluation of a collaborative care implementation using RE-AIM. Fam Syst Health 2017;35:295-307.

55. Bender BG. Nonadherence to asthma treatment: Getting unstuck. J Allergy Clin Immunol Pract 2016;4:849-51.

56. Laws RA, Jayasinghe UW, Harris MF, et al. Explaining the variation in the management of lifestyle risk factors in primary health care: A multilevel cross sectional study. BMC Public Health 2009;9:165.

57. Foster JA, Yawn BP, Maziar A, Jenkins T, Rennard SI, Casebeer L. Enhancing COPD management in primary care settings. MedGenMed 2007;9:24.

58. Davis D, Galbraith R. Continuing medical education effect on practice performance: Effectiveness 
of continuing medical education: American College of Chest Physicians Evidence-Based Educational Guidelines. Chest 2009;135:42S-48S.

59. Teach SJ, Gill MA, Togias A, et al. Preseasonal treatment with either omalizumab or an inhaled corticosteroid boost to prevent fall asthma ex- acerbations. J Allergy Clin Immunol 2015;136: 1476-85.

60. Glasgow RE, Magid DJ, Beck A, Ritzwoller D, Estabrooks PA. Practical clinical trials for translating research to practice: Design and measurement recommendations. Med Care 2005;43:551-7. 